\title{
Women's Health in Central America: The Complexity of Issues and the Need to Focus on Indigenous Healthcare
}

DATASET in CURRENT WOMEN S HEALTH REVIEWS · APRIL 2013

DOI: $10.2174 / 1573404811309010002$

CITATION

1

4 AUTHORS:

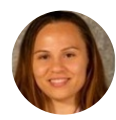

Tracie D Locklear

Duke University

22 PUBLICATIONS 103 CITATIONS

SEE PROFILE

\section{Armando Caceres}

University of San Carlos of Guatemala 108 PUBLICATIONS 2,200 CITATIONS

SEE PROFILE
Alice L. Perez

University of Costa Rica

42 PUBLICATIONS 633 CITATIONS

SEE PROFILE

Gail Mahady

University of Illinois at Chicago

131 PUBLICATIONS 2,077 CITATIONS

SEE PROFILE 


\title{
Women's Health in Central America: The Complexity of Issues and the Need to Focus on Indigenous Healthcare
}

\author{
Tracie D. Locklear ${ }^{1}$, Alice Perez ${ }^{2}$, Armando Caceres ${ }^{3}$ and Gail B. Mahady ${ }^{4, *}$
}

\begin{abstract}
${ }^{I}$ Duke Cancer Care Research Program, Duke University Medical Center, Durham, North Carolina; ${ }^{2}$ Centro de Investigaciones en ProductosNaturales (CIPRONA) and Escuela de Química, Universidad de Costa Rica, 2060, San Pedro, San José, Costa Rica; ${ }^{3}$ Universidad de San Carlos, Facultad de Ciencias Químicas y Farmacia, Guatemala City, Guatemala: ${ }^{4}$ Department of Pharmacy Practice, UIC PAHO/WHO Collaborating Centre for Traditional Medicine, University of Illinois at Chicago, College of Pharmacy, 833 S. Wood St. Chicago, IL 60612, USA
\end{abstract}

\begin{abstract}
The Central American (CA) isthmus consists of seven countries including Belize, Costa Rica, El Salvador, Guatemala, Honduras, Nicaragua and Panama, some of the poorest countries in the world. Over the past twenty years, CA has made good progress in improving the health status of their populations. Analysis of the peer-reviewed literature, as well as national and international reports show that life expectancy at birth has increased and child mortality rates have fallen. Maternal mortality ratios (MMR) have declined by approximately 33\%, however the MMRs for indigenous women remain at unacceptable levels. Despite the advances, made in many CA countries, the overall health status remains well below Latin American averages. In fact, in most CA countries, poor health outcomes are increasingly concentrated geographically among the poor and indigenous populations. Considering indigenous people make up the second largest population group in CA, any improvements in healthcare should significantly improve the health statistics for these countries. For these populations, the integration of local cultural practices and traditional healing methods with modern medicine and healthcare facilities is critical for acceptance. Investigations and analyses of local cultures, knowledge and traditional medicine practices should be used to determine the factors that contribute to poor health in these populations. Local health educational programs are needed, especially those that would involve men (spouses), families and entire communities. Furthermore, manywomen's reproductive issues still need to be addressed, particularly those that focus specifically on maternal mortality and cancer. For reductions in maternal mortality, El Salvador and Costa Rica may be good examples to follow. Access to inexpensive (or free) healthcare that is culturally sensitive and community based, particularly for indigenous women, would greatly improve the overall health. The major stumbling blocks to progress are that the funding for programs to reduce maternal mortality is woefully inadequate and that there has not been a focus on improving healthcare for indigenous women.
\end{abstract}

Keywords: Cervical cancer, maternal mortality ratio, Maya, poverty, traditional healing methods.

\section{INTRODUCTION}

Geographically, Central America (CA) is the isthmian portion of the North American continent that connects North America and South America. Central America has an area of approximately 202,000 sq. miles and a population estimated at approximately 42 million people $[1,2]$. The CA isthmus consists of seven countries including Belize, Costa Rica, El Salvador, Guatemala, Honduras, Nicaragua and Panama, some of the poorest countries in the world. The population of Central America consists mainly of four groups. The largest of which are the mestizos, a mixture of Spanish and native peoples; followed by indigenous populations; Africans; and people of European descent. Throughout much of the region, African populations tend to be concentrated along the Atlantic coastline, while mestizos populate the Pacific side. The central area of the isthmus is home to lush rainforests

*Address correspondence to this author at the Department of Pharmacy Practice, College of Pharmacy, University of Illinois at Chicago, 833 South Wood St., MC 886, Chicago, IL 60612, USA; Tel: 312-996-1669; Fax: $312-$ 413-5894; E-mail: mahady@uic.edu that are still populated by numerous groups of indigenous peoples [1-3]. In Nicaragua, Honduras, Guatemala, and El Salvador, as much as half of the population lives in poverty, while the economy is much better in countries such as Costa Rica and Panama (Fig. 1) [4]. Both of these countries have high per capita income, low unemployment, a high literacy and more favorable social development. In 2003, only 20$30 \%$ of the populations in Costa Rica and Panama were below the poverty line, while in the other CA countries approximately $50 \%$ of the population were living in poverty, with many living in extreme poverty [4].

Over the past twenty years, CA has made good progress in improving the health status of their populations. Life expectancy at birth has increased by approximately 10 years and child mortality rates have fallen dramatically to below 40 per 1,000 live births on average. In addition, maternal mortality rates have seen a decline by approximately $33 \%$ [35]. This progress is due to overall improvements in the general standard of living, the education levels, and the proportion of the population with regular access to water and sanitation services [4]. However, despite these advances, the 


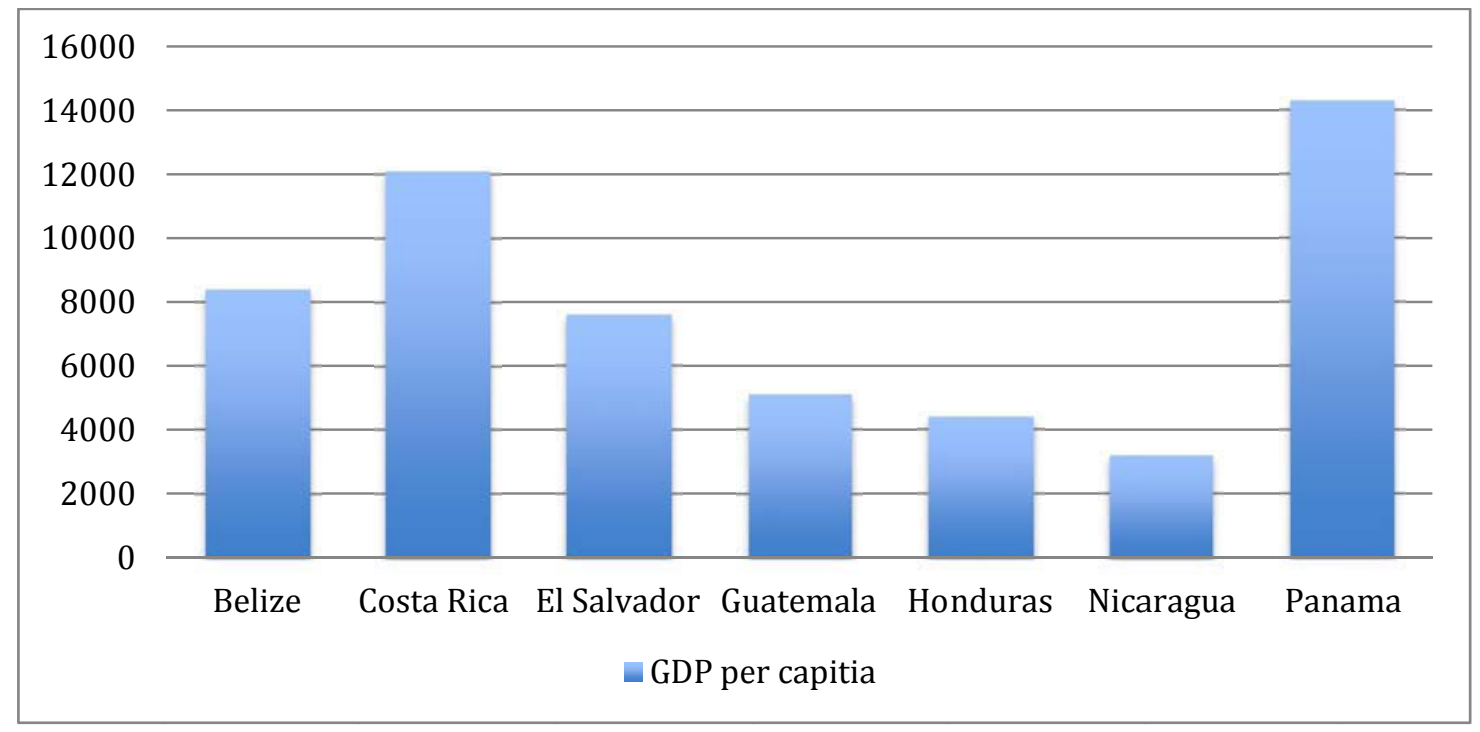

Fig. (1). GDP per Capita in Central American Countries. Adapted from the CIA Factbook 2012.

health status in several CA countries remains far below Latin American averages, especially in the four poorest countries of CA, namely El Salvador, Guatemala, Honduras, and Nicaragua. In fact, poor health outcomes are becoming increasingly concentrated geographically among the poor and indigenous populations, which are the second largest population groups in these countries $[3,4,6]$. The fragmentationof healthcare systems, the lack of financial protection of the poor, continuing gender inequality, and weak incentives of the public sector management are all important issues that need to be addressed to improve health care in all CA countries [4]. Better health care policies that do not discourage the use of community based healthcare services, traditional practitioners and trained midwives are needed in lieu of the lack of finances and acceptance by indigenous peoples. In addition, specific healthcare issues still need to be tackled in these countries, particularly those that focus on women and children.

Women in developing countries are frequently challenged with numerous socio-cultural factors that may negatively impact physical wellness and their accessibility to appropriate health care services [7]. Institutional, economic, and educational barriers impact and lower the standard of living for these women, when compared with their male counterparts. Issues such as maternal health and mortality, access to healthcare, gender inequality, health education and cultural use of traditional medicine practices still need significant intervention. This review will briefly outline some of the most current issues in women's health in CA and give specific country examples from peer-reviewed published studies, as well as national and international reports.

\section{GUATEMALA}

Found at the northern end of the Central American isthmus, Guatemala is bordered by Mexico to the north, the Pacific Ocean to the west, the Caribbean Sea and Belize to the east and El Salvador and Honduras to the southeast [8]. Seated between $13^{\circ} 44^{\prime}$ to $17^{\circ} 49^{\prime} \mathrm{N}$ latitude and $88^{\circ} 13^{\prime}$ to $92^{\circ} 30^{\prime} \mathrm{NW}$ longitude, Guatemala covers roughly 131,800 $\mathrm{km}$ (approximately equal to the U.S. state of Tennessee) [912]. The country is divided into 23 departments (or states) and 330 municipalities that are inhabited by approximately $14,655,189$ people [9]. Economically, Guatemala is among the poorest countries in CA (Fig. 1), and yet it is among one of the richest nations in terms of traditional medical knowledge and biological resources [13]. The country ranks $44^{\text {th }}$ out of 95 developing countries on the Human Poverty Index [14]. In terms of public healthcare, the Pan American Health Organization estimates that more than half of the total population lives in poverty (with $20 \%$ living in extreme poverty) and less than $60 \%$ of the population has access to public services or biomedical health care facilities [13]. Indigenous peoples make up the majority of the impoverished. In 2000, Guatemala agreed to the Millennium Development Goals (MDGs), a set of global anti-poverty and development targets that were established at the United Nations Millennium Summit [15]. The primary goal is to halve the proportion of people living in extreme poverty by 2015, from 1990 levels. However, despite these initiatives, extreme poverty in Guatemala still remains around 20\% (same as 1989). In addition to poverty reduction, other MDGs include a $50 \%$ reduction in hunger; universal primary education; promotion of gender equality and empowerment of women; reduction of child mortality by two-thirds; cutbacks in maternal mortality by three-quarters; combating the spread of HIV/AIDS, malaria and other diseases; ensuring environmental sustainability; and developing a North-South global partnership for development [15]. It is unlikely that most of these MDGs will be met for Guatemala due to inadequate funding, the country's infrastructure and political problems, as well as the wide disparity between the rich and poor.

One of the major issues for Guatemala is that it is the most ethnically diverse country in Central America, with over 20 groups of ethno-linguistic Maya origin, making up $\sim 40 \%$ of the population [2]. The majority of the Mayan populationslive in extreme poverty in remote rural areas with little access to modern healthcare facilities or practitioners [3]. Being both a women and indigenous, Maya women are 
the most marginalized and oppressed populations in Guatemala, andwhile Maya women receive some formal prenatal careand $\sim 70 \%$ of childbirths among Maya women in Guatemala are attended in the home, $74.5 \%$ of which are attended by midwives, and $5.5 \%$ without any medical assistance at all $[6,8,12]$. Guatemala's population growth is due to a very high individual expected birth rate. Less than half of all married women use contraception, and these women are expected to have at least five births during their lifetime, the highest number of the seven CA countries. Higher birth rates may be influenced by religious beliefs that do not support family planning, as well as sociopolitical concerns for the survival of the indigenous people [16]. The child ( $0-4$ years of age) mortality is estimated to be 32.8 per 1000 births in 2011(Fig. 2) [17].

The primary cause of the high infant mortality rate is the extremely limited access and affordability of healthcare services, particularly in the rural highlands where the Maya have few modern healthcare facilities available in cases of emergency and rely primarily on traditional Mayan medicine.Often just the cost of transporting a patient out of the jungle to a healthcare facility is cost prohibitive, little less being able to pay for the medical procedures themselves. Additionally, sometimes it may take days to arrange transportation out of the rural areas most often by boat. Thus, most rural births occurat home and attended are exclusively by a traditional birth mid-wife, and rural Guatemalans rely almost exclusively on herbal remedies during all stages of their pregnancy [9-13, 18, 19]. In Guatemala, a women's chance of dying from maternal causes is 75.6 per 100,000 live births (Fig. 3) [15, 17]. Maternal mortality among indigenous Mayan women in certain rural areas of Guatemala is estimated at more than five times the national average (Fig. 4). Fortunately, some community outreach strategies are showing signs of success in providing maternal

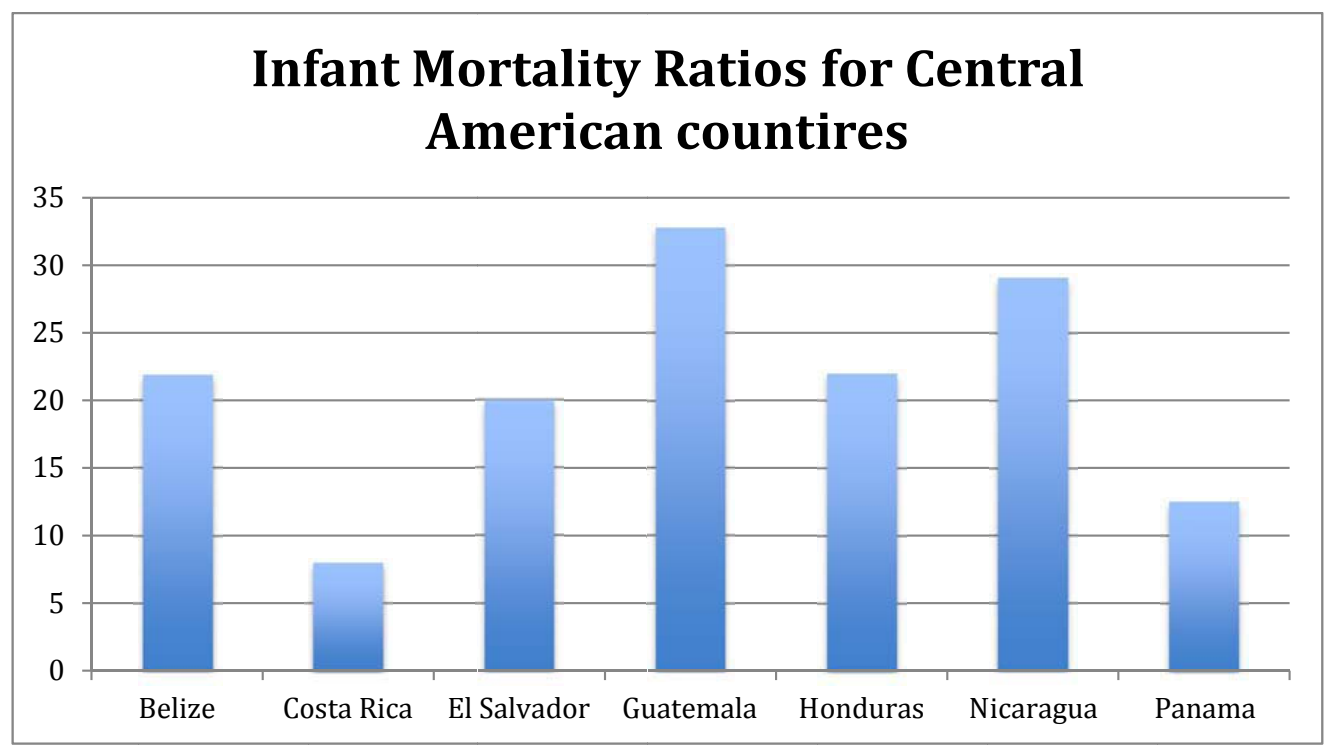

Fig. (2). Infant mortality rates in Central America per 1000 live births. Data adapted from references 15 and 17.

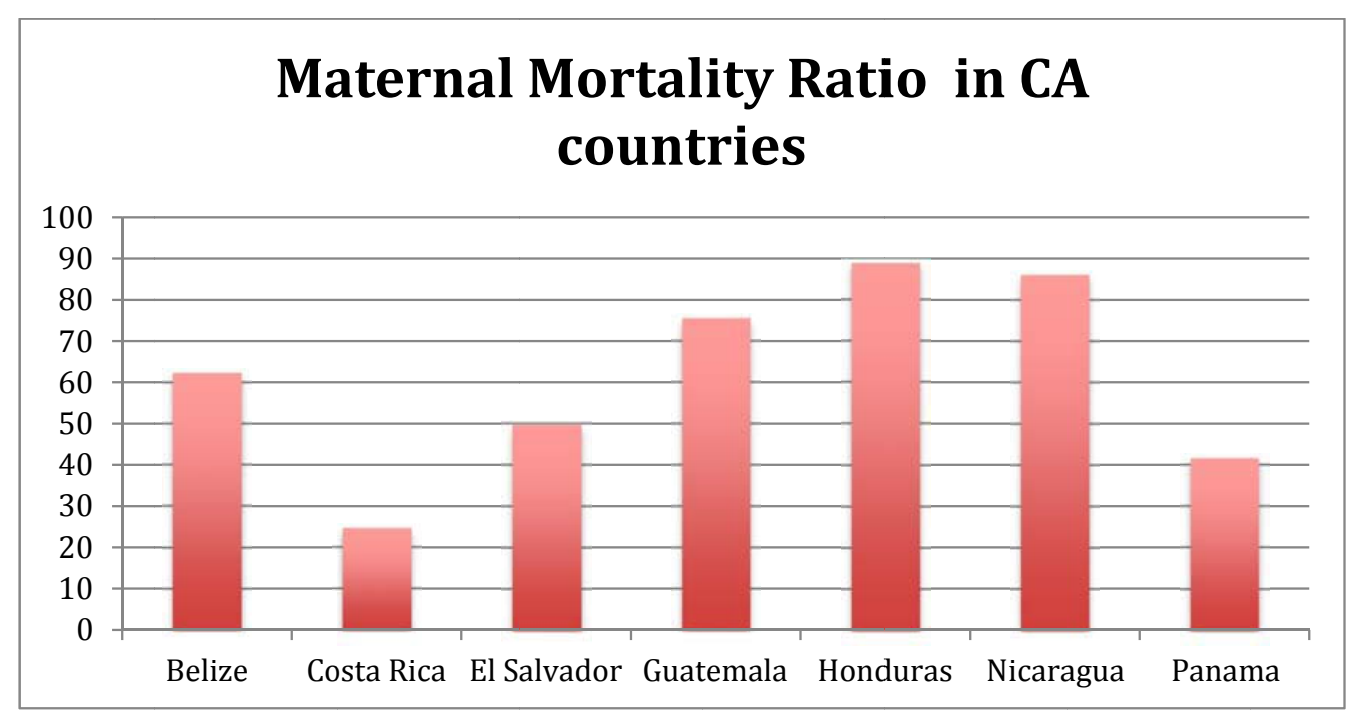

Fig. (3). The maternal mortality ratio for Central American countries. Data is presented per 100,000 live births. Data adapted from 2011 [17]. 


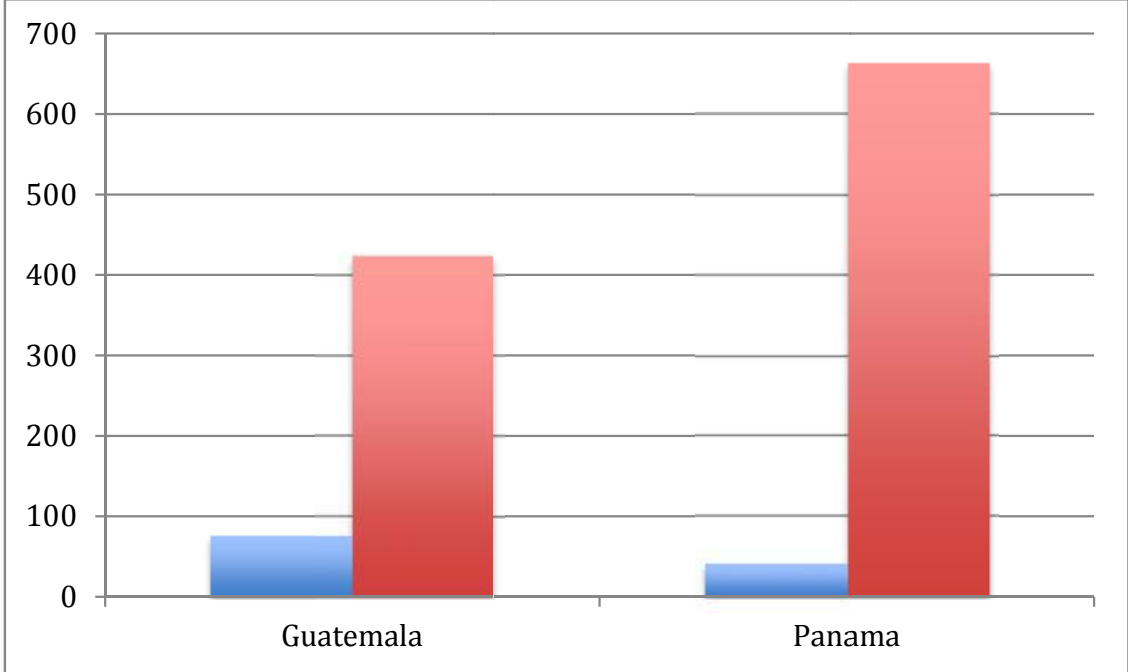

Fig. (4). The Maternal Mortality Ratio (MMR) per 100,000 live births in the general population (bar \#1) versus the MMR estimates in impoverished Indigenous populations (bar \#2).

care to the Maya women in the Guatemalan highlands, by integrating traditional medicine practices with Western medicine. One of these is the Guatemalan Ministry of Health that began an initiative to support the integration of traditional and conventional healing practices by forming a committee of healers representing each ethnolinguistic group in Guatemala [9]. However, even with these new initiatives, the maternal health-related Millennium Development Goals for 2015 will not be met for Guatemala, and high maternal mortality rates still persist.

Aside from the limited access to healthcare facilities services, another prominent cause of high maternal morbidity and mortality in Guatemala is unsafe abortions. In Guatemala, the abortion rate is $24-30$ per 1000 women, and approximately 65,000 abortions are performed yearly [20]. Unsafe abortions are the $4^{\text {th }}$ leading cause of maternal death in Guatemala. While abortion is legal in Guatemala in cases where the women's life is at risk, women rarely have abortions at public hospitals due to the negative social and cultural connotations [20]. Additionally, medical practitioners often refuse to provide contraceptives or legal abortions due to personal beliefs, further hindering access to safe abortions, by increasing the probability of illegal unsafe abortions and negatively impacting maternal morbidity and mortality [20].

Ironically although indigenous women in Guatemala are illiterate, poor, discriminated against and oppressed due to cultural and social issues, the Maya women have been called the "guardians of life and ancestral culture" [21]. Maya mothers are the initial healthcare providers for their children, husbands and other family members, and assess the symptoms and determine how to proceed with medicinal plant treatments or when to seek medical help from the community healer or nearest clinic [21]. Thus historically, these women have been the primary caregivers in families and have played a key role as healers in traditional societies, and use a range of medicinal plants and traditional knowledge for healing. Therefore, women can be viewed as the primary 'popular' or 'lay' healers in society, thus forming the backbone of traditional rural healthcare systems
[22]. However, when home remedies are not effective, women will take their children or other family member to a healer, either a Western practitioner or a Mayan Healer. But most Maya can neither afford Western clinics nor do they have a high level of regard for these clinics. In fact, many women feel disrespected due to the lack of cultural sensitivity within the clinics [21]. So even when Western care is accessible and affordable, many Maya choose not to use it and opt for traditional Mayan healers. This is a serious issue as with the exception of the research of a few investigators $[9-13,18,19]$, very few studies in Guatemala have scientifically investigated the safety and efficacy of herbal remedies used in women's health. In 2002, the national program "Popular Traditional Medicine", affiliated with the Ministry of Public Health and Social Assistance was started to raise awareness of Mayan medicine among healthcare workers. However, there is no funding available needed to perform the type of biomedical research needed to assess safety and efficacy of Mayan traditional medicines. Thus, the majority of the botanicals used in Guatemala, including those used for the treatment of women's reproductive health, have not been systematically documented or even tested for safety and possible efficacy. Considering that a large portion of the female population of Guatemala are treated with these botanical medicines and appear to prefer the use of traditional medicines and healers, there is an immediate need to document this information, collect the plant species used, and scientifically test the most commonly used plant species in a rational and systematic manner.

\section{COSTA RICA}

In contrast to Guatemala, Costa Rica is a modern model for Central America in that it is politically stable, actively promotes education to all citizens (Fig. 5) and has a relatively high standard of living as compared with other CA countries. It is an unusual developing country in that only $1 \%$ of its population is still indigenous; it has a very high literacy rate $(94 \%)$ and,over the past ten years there has concerted effort focused on improving healthcare [2-3, 23]. 


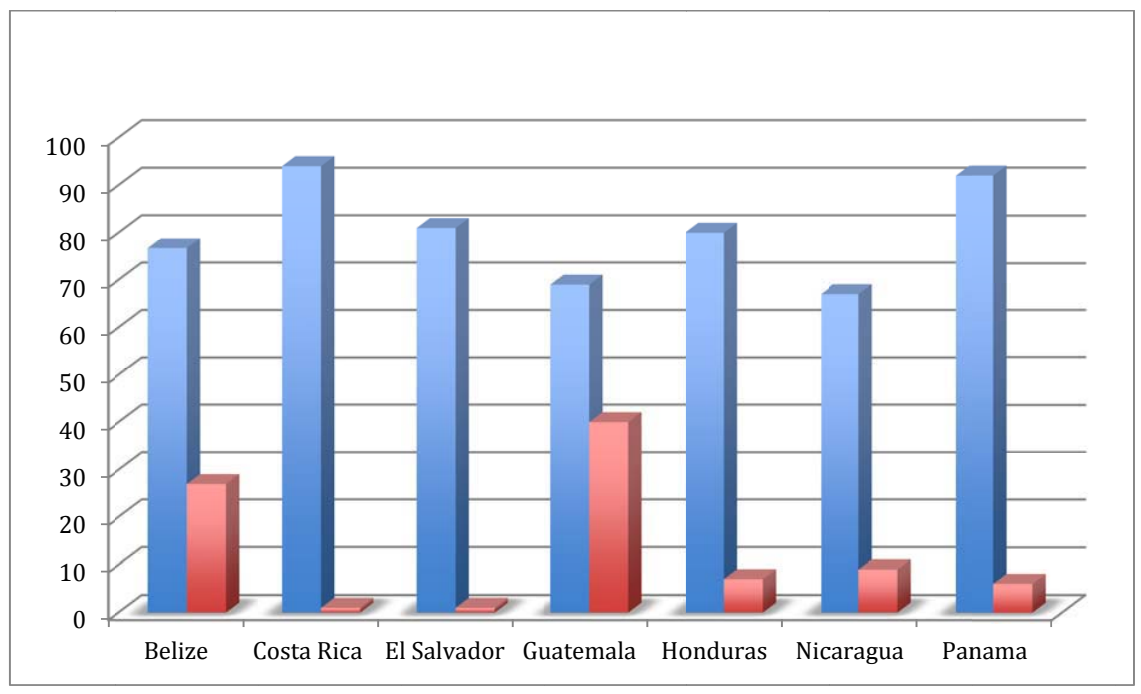

Fig. (5). Literacy rates (\%) in the general population in Central America (bar \#1) versus percent indigenous populations (bar \# 2) for each country.

Costa Rica has been able to maintain a successful public health delivery system alongside a private one [24], and has a monopoly over public health insurance. Costa Rica currently spends approximately nine times less on health per capita than the USA yet has a similar life expectancy. Its excellent outcomes in the health sector appear to be linked to the organization of its health service and the way they are funded [24]. In addition, over the past 18 years, Costa Rica has implemented health care programs specifically focused on the improvement women's health, particularly in the field of reproductive health and actively promotes high coverage of institutional deliveries and prenatal care [25]. These programs appear to be working, as the infant mortality rate in Costa Rica is very low (24.6 per 100,000 live births), almost half of that observed in Panama (41.6 per 1000,000; Fig. 3) $[17,26]$. Interestingly, a 2008 study of prenatal health care knowledge, showed that Costa Rican women were much more knowledgeable about necessary prenatal care than Panamanian women suggesting that direct education and promotion of prenatal care, as well as the promotion of education for women helps to reduce infant mortality [26].

Costa Rica, like most other CA countries, faces future key challenges associated with the rapid increases in ageing, such as increases in cardiovascular disease, control and treatment of cervical cancers, breast cancer, poor nutrition, mental health, and the problems associated with menopause [27]. Women in Costa Rica enter menopause around the age as women in the U.S., and have a similar problems with symptoms. Numerous women's groups and physician's association in Costa Rica have been organized to specifically address the fact that ageing women and the chronic sequelae of menopause will be a problem for Costa Rica in the near future [27]. However, while the symptoms of menopause are reported to be high and osteoporosis is a problem due to poor nutrition, there are no published studies to date assessing the symptoms and attitudes associated with the menopausal transition. A 2011 report assessed the knowledge, perceptions and attitudes of middle-aged women in Costa Rica, Panama, Nicaragua, Honduras and El Salvador concerning the treatments for menopause [28]. Knowledge of treatments varied significantly among women. Approximately $27.2 \%$ (196/720 participants) knew hormone therapy (HT) was an option, while $36.3 \%$ were unaware or did not respond. HT use was extremely low, only $2.7 \%$ with minor differences between countries. Of the group that knew about hormone therapy, $13.8 \%$ stopped using HT due to medical contraindications, adverse events and the cost. Approximately 14\% thought that HT was not good for their health, while $10 \%$ of women knew about phytoestrogens (plant based estrogens) and 25\% thought they were good for women's health [28].

In Costa Rica, medicinal plants continue to be the most economically and culturally suitable treatment for a wide variety of health conditions, including those related to women's health and menopause [29]. However, again many of these medicinal plants have neither been thoroughly documented, nor has research on their biological potential and phytochemical profile been performed. These data would provide important information on the safety and efficacy of these plants, not only for women living in Central America, but also for women worldwide who are searching for alternative natural therapies for menstrual and menopausal problems $[9-12,23,29]$.

\section{NICARAGUA}

Nicaragua has a population of 5.4 million people and is the poorest country in CA [2]. The population is unevenly distributed with the majority of people being concentrated in the Pacific region, which occupies $15.3 \%$ of the national territory but has $61.5 \%$ of the total population (with poverty levels ranging from $5 \%$ to $24 \%$ ) and $76.4 \%$ of the urban population [30]. The central region, with $33.9 \%$ of the total area, has $32.6 \%$ of the population (with poverty levels ranging from $15 \%$ to $35 \%$ ), with most inhabitants living in rural areas. The Atlantic region, which occupies $50.9 \%$ of the national territory, has only $5.9 \%$ of the total population, with poverty levels ranging from $35 \%$ to $45 \%$ [30]. The 2010 extreme poverty levels were at $14.6 \%$ and the country is halfway to achieving this MDG. It has a literacy rate of $68 \%$ 
and a child mortality rate of 29.1 per 1000 live births as of 2010 (Fig. 2) [17]. The education rate of women is approximately 64\% [30]. Life expectancy at birth increased from 48.5 years in the period $1960-1965$ to 66.2 years in the period between 1990 and 1995. In rural areas, life expectancy is almost 10 years lower, although females have a higher life expectancy than males [30]. The estimated birth rate for the five-year period 1990-1995 was 40.5 per 1,000, and the fertility rate was three children per woman, very similar to Guatemala. The official statistics on the maternal mortality ratio are high, approximately 86.0 per 100,000 live births (Fig. 3) [17]. The causes of maternal death are associated with conditions that generally develop in the latter half of pregnancy, such as hemorrhage, hypertension, and sepsis, although like Guatemala, abortion is also a serious cause of maternal mortality. High maternal death rates are also linked to the prevalence of several reproductive risk factors in the female population, notably the large number of children per woman and high specific fertility rates in women under 19 and over 35 years of age. Adolescent pregnancy accounts for almost $28 \%$ of all pregnancies in Nicaragua [2].

One 2007 study investigated the concepts of health and illness as perceived by impoverished Nicaraguan women [31]. The health concepts of these women included activity, good disposition, good nutrition and healthy appearance. Health maintenance activities included good hygiene and sanitation, medical intervention when needed, and personal cleanliness [31]. These women practiced health care prevention in terms of eating well, getting lots of physical activity and using good personal hygiene. They also recognized the importance of sanitation and health [31]. One of the "unhealthy conditions" recognized by Nicaraguan women is described as thin and pallid with physical failing [32]. This is a very interesting observation by the women, as anemia is an important health problem in CA affecting as much as $19 \%$ of the entire population, predominately women and children [32, 33]. In a 2008 study on anemia in Nicaragua, researchers discovered that approximately $35 \%$ of pregnant adolescent girls had anemia [34]. In a follow up study published in 2009, these researchers found that lowincome women in Nicaragua did not know the symptoms of anemia but knew that improper eating and a lack of vitamins caused anemia [32]. When asked what they would use to treat anemia the women mentioned foods such as bean soup and milk, and a number of traditional Nicaraguan medicines that produce a molasses type of extract. However, methods of food preparation, excessive coffee drinking and the lack of meat products, due to extreme poverty, maybe a hindrance to reducing anemia in these populations [32].

In terms of the knowledge and use of traditional Nicaraguan medicines (herbal medicines) in Nicaragua, a few studies have found that some medicinal plants are widely recognized in Nicaragua and herbals were used in groups with lower socioeconomic status and ethnic origins [35-38]. Results from the 2004 study by Ailinger and coworkers [35] found that $78 \%$ of households in a Nicaraguan barro used herbal remedies and many people reported that they used these products not only because they could not afford allopathic medicines, but also that the herbal medicines worked well [35].

\section{HONDURAS}

Honduras is bordered to the west by Guatemala, to the southwest by El Salvador, to the southeast by Nicaragua, to the south by the Pacific Ocean at the Gulf of Fonseca, and to the north by the Gulf of Honduras, a large inlet of the Caribbean Sea [1-3]. Honduras has a population of $8 \mathrm{M}$ and is home to several important indigenous cultures, most notably the Maya. Like many of the other CA countries, poverty is also a primary problem in Honduras with $60 \%$ of the population living below the poverty line. The rural areas are even more poverty stricken with $72.2 \%$ living in poverty and even worse for the $84 \%$ of the Lenca, the country's largest indigenous group, who live in extreme poverty [39].

Women's health in Honduras is influenced by many factors including socioeconomic status, indigenous identity, poor education, and rural versus urban living [39]. This is reflected by the fact that infant mortality is approximately 22 per 1000 in Honduras and maternal mortality is 88.8 per 100,000 live births (Figs. 2 and 3) [17]. A rare report published in 2011, investigated women's health disparities in Yamaranguila, a Lenca rural area, by interviewing 134 Lenca women [39]. Of the women interviewed, 56\% rated their overall health as only fair or poor. Good health was correlated with a history of having a Pap smear or seeing a traditional healer, but not associated with having seen a doctor. Of the women reporting poor health, $>80 \%$ thought that better access to health services would improve overall health [39]. While $88 \%$ of women knew about Pap smears, only $50 \%$ of women had ever had one, and only 1 in 9 women had ever had a mammogram [39]. Interestingly, the majority of the women interviewed had reasonable prenatal care, unlike Guatemala and Nicaragua. Approximately 33\% of women did not give birth in a hospital or clinical, which is significantly lower than that of either Guatemala or Nicaragua $(\sim 70 \%)$ [39]. Women receiving four or more prenatal care visits were more likely to have given birth in a hospital or private clinic. But, $60 \%$ of births that occurred outside of the hospital were among mothers living in the remotest regions with poor access to hospitals [39]. The results of this study again demonstrate that indigenous women lag behind non-indigenous peoples in terms of women's reproductive health and healthcare. Poorer health of the women in this study was associated with poor living conditions, contaminated water supplies, poor quality food and suboptimal healthcare services. Women's health in Honduras is influenced by many factors including socioeconomic status, indigenous identity, poor education (Fig. 5), and rural versus urban living [39].

In another study, researchers investigated the risks to maternal health in remote Honduran Miskito communities along the Ibans lagoon in the Rio Platano Biosphere Reserve [40]. In these communities, large families are considered the ideal with more than eight births per woman, and most women give birth at home with a midwife, family member or nurse. They tend not to leave the villages to give birth at hospitals, and health center personnel rarely attend births. Threats to maternal and infant health in these communities included the lack of adequate healthcare resources and facilities. Most maternal deaths weredue to severe bleeding, prolonged labor, and infection, all which are considered 
treatable when given adequate health services [41]. In some cases, the women and family members often did not seek help from healthcare providers until complications worsened. The maternal death rate was also associated with cases of hepatitis, tuberculosis, hemorrhagic fever and anemia. In addition, the distance and high cost ( $\sim 275$ USD) of travel to the hospitals, significantly impacts maternal mortality as many women die while waiting for transport to hospital [40], making abject poverty a cause of maternal deaths in these remote villages. Other causes of maternal deaths included: domestic violence; beliefs in witchcraft or sorcery as causes of illness; men's beliefs about finances; and women's responsibility for their own health. Healthcare personnel attributed maternal mortality to insufficient local health services and the difficulties in convincing women to seek care at hospitals if they are high-risk. The study also indicated that women were more likely to use healthcare services if they were offered locally and they did not exclude Miskito traditional healing methods [40].

Disturbingly, cervical cancer rates in Honduras are also very high, although this is true throughout CA [39]. While Pap smears can successfully impact the outcomes of cervical cancer, the infrastructure, money and technologies needed for the screening programs is often lacking in most CA countries. A case in point is the fact that Pap smears in Honduras have been shown to be of little diagnostic value due to their poor quality of the specimen sampling, analysis and follow up. According to the International Agency for Research on Cancer (IARC), no organized national or international cervical cancer screening programs in exist in Honduras, Guatemala, El Salvador or Nicaragua [39]. Considering the disproportionate burden of cervical cancer in these countries, a high priority of national and international programs should be increasing the availability of quality Pap smears in countries where cervical cancer is problematic.

\section{PANAMA}

Panama is the southernmost country in the CA isthmus connecting North and South America. Due to the presence of the Panama Canal, Panama has the third largest economy, the fastest growing economy and the largest per capita consumer in CA [2]. As of 2010, Panama had a population of 3,405,813, which consisted of: "mestizo (mixed Amerindian and Caucasian) 68\%, Black (West Indian) 10\%, Caucasian 15\%, Asian 1\%, Amerindian 6\%" [2]. The Amerindian population includes seven indigenous peoples: the Emberá, Wounaan, Ngöbe Buglé people (formerly the Guaymí), Guna, Naso, and the Bribri. In Panama, the lifetime average number of children per women is three, but there islittle data available concerning contraceptive use in this country [41]. Only $1 \%$ of women aged 50-69 years have undergone a breast examination or mammography and only $3 \%$ of women aged 20-69 years have undergone cervical cancer screening. The maternal mortality ratio for Panama is moderate with 41.6 deaths per 100,000 live births (Fig. 3; ranking among the ten best countries in Latin America) [17], but in some of the primary indigenous areas, the death rate is significant and is suggested to beas high as 658 per 100,000 (Fig. 4) [41]. Social and economic indicators place the country among a group of relatively wealthy middle-income countries, although $40 \%$ of the population lives in poverty and are mainly the indigenous populations. On average 92.5 per cent of births in Panama were attended by skilled medical personnel, howeveronly 57.4 per cent of births by indigenous mothers received any medical attention. Most indigenous women give birth to nine or more children, as many of these women do not use birth control methods, either for religious reasons, or because they are fearful that their husband will leave them if they do [41].

High maternal mortality rates in Panama are associated with extreme poverty, marginalization and inequality [41]. An estimated $98 \%$ of the indigenous population in Panama lives in extreme poverty, defined as living on less than $\$ 2$ per day. The use of hospitals for births is not common for these indigenous groups for many reasons that have been a common theme throughout this review. One interesting issue that has been cited is that indigenous women are used to giving birth standing up, or squatting, not lying down as in Western clinics or hospitals. This practice is almost never used in hospitals, and most of the medical staff have never been trained for this type of delivery [41]. In addition, indigenous women also sometimes experience racial discrimination in urban hospitals, often preventing these women from feeling comfortable going to a hospital to give birth.

\section{EL SALVADOR}

El Salvador has a population of 6.5 million people, $45 \%$ of who live in rural areas [42]. Life expectancy in El Salvador was approximately about 70 years in 2005, and $80 \%$ of the population are literate [2]. Approximately $21 \%$ of the population lives below the international poverty line. El Salvador, like most other CA countries, is characterized by gender inequity that generally favors men socially, economically and politically, although some progress has been made in the area of education for women. Childbearing patterns in El Salvador have changed considerably and the total fertility rate fell from about 6.3 children per woman in the mid-1970s to 2.9 children in the late $1990 \mathrm{~s}$, and is now stable at two children per woman [2, 42]. In a 2002-2003 survey, approximately $67 \%$ of married women said that they or their partner were using a contraceptive method, of which the most common was female sterilization (33\%) followed by injectable and oral contraceptives. Approximately $75 \%$ of women obtained contraception from government health services. However, unintended and teenage pregnancies are problematic health and social issues in El Salvador [3]. In 2011, the Ministry of Health in El Salvador reported that the country had met MDG 5 calling for a reduction in maternal mortality to 50.8 per 100,000 live births 2015. Maternal deaths in El Salvador have dropped from 71.2 per 100,000 live births in 2006 to 49.5 per 100,000 live births in 2011 [17]. The government of El Salvador achieved this milestone by providing a geographically accessible free health services, as well as the training of healthcare personnel.

Along with other CA countries, cervical cancer is also a serious problem in El Salvador, which has an incidence rate of 40.6 per 100,000, which is as high as Nicaragua [43]. A study of the cervical cancer screening program in El Salvador showed that in the clinics generally had insufficient 
supplies for Pap smears; poor uptake and loss of samples; slow turnaround time of results (1 month or more), and poor record-keeping as well as a laboratory reading backlog, and poor quality control [43]. These problems are disturbing considering the high rate of cervical cancer in $\mathrm{CA}$, and need to be addressed with priority.

Another issue that has been poorly addressed in most CA countries is that of osteoporosis. While countries such as Costa Rica and Guatemala report a low incidence of osteoporosis [23], many cases of osteoporosis may actually be misreported as dorsalgy, a disease state that includes several musculoskeletal disorders. In El Salvador, osteoporosis may be reported as dorsalgy [44]. According to a report from 2001, dorsolgy was the $7^{\text {th }}$ most frequent cause of morbidity in women aged 50-59 years in outpatient clinics in El Salvador, with an incidence of $\sim 4000$ new cases per 100,000 [45]. A 2004 study assessed the knowledge of women concerning osteoporosis [44]. Of the women surveyed, women with primary or no education increased with age, and $61 \%$ of the women lived in poverty. Approximately $75 \%$ of women interviewed had a basic understanding of osteoporosis, with $44 \%$ of women reporting a familial history of the disease. Almost $75 \%$ of women surveyed obtained less than $600 \mathrm{mg}$ of calcium per day, independent of income. Women with a better education had significantly better knowledge of osteoporosis [44].

\section{BELIZE}

Belize is the smallest country on the CA isthmus, boarded on the north by Mexico, on the west and south by Guatemala. The total country population is estimated at $\sim 340,204$ [2-3]. The country's population is divided between $52 \%$ rural and 48\% urban and here are approximately 102 males for every 100 females. The population is ethnically and culturally diverse, with a majority of Mestizos (48.7\%) and Creoles $(24.9 \%)$; populations of indigenous Maya $(10.6 \%)$ and Garinagu (6.1\%); and other minorities, including Mennonites, East Indians, and Chinese [5]. After the age of 65 , the male to female ratio shifts to a slightly higher population of women. Age distribution of the population shows that it is quite young with a median age of 18.9 years, approximately $42 \%$ of the population is under age 15 , and $60 \%$ is under age 25 [30]. English is the official language, but Spanish, Creole, and Garifuna are also spoken. According to the World Health Organization, the basic literacy rate is high (Fig. 5), [46] and 33\% of Belizeans were considered poor (unable to meet expenses for basic food and supplies) [47]. The reported total fertility rate is three children born/woman [2] and the maternal mortality rate is 62.3 per 100,000 live births (Fig. 3) [17].

Like other countries in CA indigenous women are at higher risk for morbidity and mortality due to poor access to clinics and hospitals, and practicing physicians. Midwives are available but high-risk deliveries must be transported out of district to facilities that can mange these deliveries [47]. Despite these limitations, emergency transfers from the Toledo District (highest indigenous population) are rare, and most pregnant women deliver at home without medically trained assistance [47]. Since 1957, traditional birth attendants (TBAs)have been trained in Belize by the
Ministry of Health (MOH). The Belize $\mathrm{MOH}$ offered six months of midwifery instruction to women who were known in their communities to already be knowledgeable in midwifery. After training, the $\mathrm{MOH}$ would recognize women as certified birth attendants. The World Health Organization asserted that the training of TBAs was a good means to reducing maternal mortality rates in poor, developing countries, where childbirth outside of medical facilities is common practice. The TBAs were trained under a standardized program that included recognition of biomedically-defined risk factors and referrals for high-risk pregnancies [47]. In 1999, the government of Belize discouraged the training of midwives, and as a consequence, fewer and fewer practicing T.B.A.s are available to assist labor and delivery in the remote villages where the majority of indigenous women live.

Early pregnancy (many indigenous women marry in their early teens) and too many young single mothers are problems in Belize and HIV infections are surprisingly high, particularly with drug resistant HIV [48]. According to a 2010 UN report, Belize has the highest HIV prevalence in $\mathrm{CA}$ and the third highest rate in the Caribbean, with estimated adult prevalence of $2.1 \%$ and AIDS is the leading cause of death in the 15-49 population [49]. In 2009, the number of new infections had declined by $14 \%$ from the 2008 levels, thus allowing Belize to reach one of its MDGs. Improvements in testing, treatment and the testing of pregnant women for HIV were all implemented and contributed to the decline. An educational program entitled "Together we can", an HIV Peer Education Program of the Belize Red Cross focused on training school and health counselors and peer educators. This program was funded by the United Nations Development Programme in Belize and demonstrates that with significant funding and organization, education can make a difference in healthcare outcomes.

\section{REPRODUCTIVE ISSUES COMMON TO ALL CA COUNTRIES}

The poorest countries of Central America have limited means to improve maternal and infant health care and achieve MDGs by 2015. In the past, government and private donor support significantly contributed to reducing maternal and infant deaths [40]. However, despite the progress that has been made, the maternal death rates and plight of women's health in all CA countries, with the exception of Costa Rica, are still poor as compared with other Latin countries. Today, maternal death and disability remain a leading cause of healthy life-years lost for womenof reproductive age in low-income countries. In 1996, approximately 585,000 women died of maternal causes, with $99 \%$ of them in developing countries [24]. In 2005,536,000 women were still dying of maternal causes, and $99 \%$ of these women were in the same countries [24]. In 2000, the Millennium Declaration was signed and countries committed to achieving eight goals for development [15]. The target for MDG 5 was to reduce the maternal mortality by threequarters by 2015 . Of the CA countries, only El Salvador has managed to achieve this goal by focusing on the provision of free accessible healthcare and the training of health care professionals. 
According to the UN MDG Report, since 1990 there has been a $47 \%$ decline in maternal deaths globally [15]. However, the progress in reducing maternal mortality has been much slower than anticipated and the expectation is that most developing countries will not achieve the MDGs for maternal mortality by 2015 [15, 17]. In an attempt to increase the progress in reducing maternal mortality, the UN Secretary-General launched the Global Strategy for Women's and Children's Health in September, 2010. Donor nations and other organizations have committed US $\$ 40$ billion to this effort to accelerate progress. The 2012 MDG Report published by the United Nations shows that progress has been made in most of the eight MDGs worldwide, but note that important improvements in maternal health and reduction in maternal deaths has been slow and are far from the 2015 targets [15]. They further note that funding for these programs is KEY to their success, but funding to aid reproductive health has actually declined over the past 10 years. With the exception of Costa Rica, inadequate fundinghas been allocated to health infrastructure, training programs and management in all CA countries [50]. In order to achieve good maternal health and delivery outcomes money for the provision of comprehensive care for mothers to provide clinics for antenatal care, the treatmentof complications and rapid referral; peripheral maternity units, district and regional hospitals is necessary. But the implementation of such facilities and services requires a high level of commitment by governments to systemic change, capacity-building, long-term investment in infrastructure and public services [50].

Considering the importance of healthcare for women, there is a shocking lack of funding for women's health in general. Hundreds of millions of dollars are made available for the management and treatment of diseases HIV, Malaria, and Tuberculosis on an annual basis, yet funding for the most basic of all human healthcare needs-that of birth, is woefully inadequate. Over the past 20 years, maternity services in developing countries have been some of themost grossly underfunded programs [51]. However, there also appears to be very little in the way of funding for cancer screening for women in developing countries as well. Considering women in CA have very high incidence of cervical cancer, adequate cancer-screening services also should be another high priority for funding agencies and governments. It is possible that a government run, tax-based, publichealth system with universal access, free at the point of care (such as has been implemented in El Salvador) may be the least expensive and the most equitable way to go for these countries.

\section{PROGRESS IS NEEDED IN INDIGENOUS WOMEN'S HEALTH}

Progress toward improved indigenous healthis much more complicated and has been hampered by a lack of access to local healthcare services, poverty, gender inequity, ethnic inequity, superstitions, as well as poor living and public transportation conditions $[5,7]$. Indigenous women are most often the victims of extreme poverty, gender inequality, ethnic discrimination, and lack the financial resources and authority to seek prenatal and obstetric care [40]. They often will not use clinics as Western trained healthcare workers often lack the cultural sensitivity, local knowledge and understanding of indigenous traditional medicines needed to provide adequate healthcare to these populations [40, 41]. Indigenous women often feel disrespected and looked down upon by Western healthcare professionals. A matter exacerbated by the fact that most Western health workers do notspeak indigenous languages, making it difficult for women to explain their symptoms. Indigenous people often fear and mistrust modern medicine creating a disincentive for them to obtain Western treatments [40]. In addition, most Western health centers may have restricted or inconvenient hours, and therefore women are prevented from seeking modern medicalservices, especially when they are faced with long waiting periods at the health centers. Women usually prefer the services of traditional midwives (comadronas) rather than nurses and doctors, because these women incorporate traditional cultural beliefs and medicinal plants into their work $[40,41]$. However, most midwives often are not trained for complicated pregnancy and deliveries, which may further endanger women's lives. Throughout this review we have shown that maternal mortality in indigenous populations extremely high when compared with that of the rest of the population of CA countries. Thus, if indigenous women's health remains ignored, the reductions in maternal mortalities required by the MDG will never be achieved, particularly in CA countries with high indigenous populations. A serious concern is the use of plant based traditional medicines during pregnancy that is commonly practiced during the prenatal, delivery and postnatal periods in most indigenous communities, however most of these herbs have never been scientifically tested.

Historically, women are the providers of medical care and the transmitters of medical knowledge and beliefs in indigenous societies. They play a critical role in the health of the entire community, particularly the children, all of whom are taken care of exclusively by their female family members. However, indigenous women often have the lowest literacy rates (Fig. 5) and less completed school years than men [3]. Further complicating the issues, are the indigenous men's attitudes that prevent women's accessinghealth services. Indigenous men may prevent their wives from seeking modern medical services for themselves or their children, largely for the same reasons that women themselves do not seek modern health services. For example, indigenous men may prevent women from obtaining contraception because it is not in keeping with cultural and religious practices of the indigenous communities. Also, the inability to pay for simple transportation and health services due to the extreme poverty in these groups is prohibitive to obtaining healthcare. Even where healthcare services are free, indigenous peoples may not be able to pay for costs of travel to such clinics and hospitals.

The importance of culture and traditional healing methods on indigenous women's health should not be underestimated. Investigation and analysis of local cultures, knowledge and traditions may be used to determine factors that contribute to poor health in these populations. Gender inequality is still a serious problem in all countries. Since many women are poor and lack the financial resources and authority to seek healthcare, educational programs and interventions that would also involve men, families and 
entire communities are necessary [52]. Culturally appropriate healthcare interventions that could be obtained locally, and that are integrative in their approach and that address the concerns of women, their spouses and their families are urgently needed. Implementing such an approach would not only be more effective and less costly than trying to provide everyone with Western medicine, but would likely be much more culturally acceptable for all involved. Considering that Guatemala and Belize have the highest indigenous populations, high priority should be given to these countries.

Taking into account the critical role that women play in the overall health and well-being of their entire communities in CA countries, as well as the fact that the goals of Maternal Health related Millennium Development for 2015 will not been met for most CA countries, it is time to shift the focus to women's reproductive health. National and international organizations, especially the governments, Pan American Health Organization and the World Health Organization, should focus their time, efforts and finances to projects that will improve the health of women, especially indigenous women's health, which would ultimately facilitate achieving the MDG for maternal mortality in these countries. A redirection of some funds from the malaria, HIV and tuberculosis projects to facilitate improvements maternal and child health would reach more people and have a significant impact on world health.

\section{CONFLICT OF INTEREST}

The authors confirm that this article content has no conflict of interest.

\section{ACKNOWLEDGEMENTS}

Declared none.

\section{REFERENCES}

[1] World Bank. Nicaragua country brief. 2004.http://web.worldbank. org. Accessed October 8, 2012

[2] CIA - The World Fact book". CIA.gov. Accessed September 23, 2012.

[3] Pan American Health Organization, Health situation in the Americas: Basic health indicators. 2012 http://new.paho.org. Accessed October 15, 2012

[4] La Forgia GM, Ed., In: Health Systems Innovation in Central America. World Bank Report \# 57, The International Bank for Reconstruction and Development, World Bank 2012.

[5] World Health Organisation. Make every mother and child count. The World Health Organisation annual report for 2005. WHO Publications, Geneva, Switzerland, 2005.

[6] Pan American Health Organization. Maternal and child mortality among the indigenous peoples of the Americas. Bull Indigenous Health 2004; 1: 1-3.

[7] World Health Organisation. Maternal mortality in 2005. Estimates developed by WHO, UNICEF, UNFPA and the World Bank, WHO Publications, Geneva, Switzerland, 2007.

[8] Villar Anleu, L. La Flora Silvestre de Guatemala, Guatemala City: Editorial Universitaria, Universidad de San Carlos, 1998.

[9] Michel JL, Mahady GB, Veliz M, Soejarto DD, Caceres A. Symptoms, attitudes and treatment choices surrounding menopause among the Q'eqchi Maya of Livingston, Guatemala. Soc Sci Med 2006; 63(3): 732-742.

[10] Michel J, Duarte RE, Caceres A, et al. Q'eqchi Maya medicine for women's health: In vitro evaluation of Guatemalan plants in estrogen and serotonin bioassay. J Ethno pharmacol 2007; 114(1): 92-101.

[11] Michel JL, Chen Y, Zhang H, et al. Estrogenic and serotonergic butenolides from the leaves of Piper hispidum Swingle (Piperaceae). J Ethnopharmcol 2010; 129: 220-6.
[12] Michel J, Caceres A, Yao, P, et al. Q'eqchi Maya medicine for women's health: Guatemalan plants with estrogen and serotonin activities. ActaHorta 2012 [Epub ahead of print].

[13] Caceres A, Menendez H, Mendez E, et al. Antigonorrheal activity of plants used in Guatemala for the treatment of sexually transmitted diseases. J Ethnopharmacol 1995; 48: 85-88.

[14] United Nations Population Fund. Country profiles for population and reproductive health: policy developments and indicators. Maternal mortality statistics by region and by country, 2005 .

[15] United Nations. The millennium development goals report. New York, 2012.

[16] Hughes J. Gender equity and indigenous women's health in the Americas. PAHO Report 2004. www.paho.org. Accessed Oct 12, 2012.

[17] Lozano R, Wang $\mathrm{H}$, Foreman KJ, et al. Progress towards Millennium Development Goals 4 and 5 onmaternal and child mortality: an updated systematic analysis. Lancet 2011; 378: 1139-65.

[18] Caceres A, Jauregui E, Herrera D, Logemann H. Plants used in Guatemala for the treatment of dermatomucosal infections. 1: Screening of 38 plant extracts for anticandidal activity. J Ethnopharmacol 1991; 33(3): 277-283.

[19] Orellana SL, Indian Medicine in Highland Guatemala. Albuquerque: University of New Mexico Press, 1987.

[20] Kestler E. Obstetrician-gynecologists knowledge of and attitudes toward medical abortion in Guatemala. Int. J. Gynecol Obstet 2012; 116: $120-3$

[21] Giralt A. A decade after Guatemala's agreement on identity and rights of indigenous peoples: Mayan-Tz'utujil Women's views on health, healing and disease. Health Care for Women Int 2012; 33(5): 440-56.

[22] Kothari B. The invisible queen in the plant kingdom: Gender perspective in ethnobotany. In: Women and plants: Case studies on gender relations in biodiversity, eds. P. Howard-Borjas. London, Zed Press, 2003.

[23] Locklear TD, Doyle BJ, Caceres A, Perez A, Mahady GB Menopause, a Universal Female Experience, Lessons from Central America. Current Reviews in Women's Health 2007; 4: 1-10.

[24] Unger JP, Van Dessel P, Sen K, De Pape P. International health policy and stagnating maternalmortality: is there a causal link? Reprod. Health Matters 2009: 17: 91-104.

[25] Bixby LR. Assessing the impact of health sector reform in Costa Rica through a quasi-experimental study. Rev PanamSaludPublica 2004; 15: 94-103.

[26] Guilford WH, Downs KE, Royce TJ. Knowledge of prenatal care among Costa Rican and Panamanian women. Rev. PanamSaludPublica. 2008; 23(6): 369-76

[27] Pan American Health Organization. Country profiles Nicaragua. Washington DC, 2003

[28] Tserotas K, Hernandez L, MoreraF, Pineda R, Chedraui P. Treatment for the menopause in Central America: use, knowledge, perceptions and attitudes among urban living middle-aged women. Gynecol Endrocrinol 2011; 27(7): 504-11.

[29] Doyle BJ, Frasor J, Perez A, Locklear TD, Mahady GB. Estrogenic and antiestrogenicactivities of plant extracts from Costa Rica, used for the treatment of menopausal symptoms. Menopause 2009; 16 (4): $748-55$

[30] Pan American Health Organization. Traditional Health Systems in Latin America and the Caribbean: Base Information Technical Project Report, 1998

[31] Ailinger RL, Gonzalez R, Zamora L. Health and illness Concepts among lower income Nicaraguan Women. Qualitative Health Research 2007; 17: 382-5.

[32] Ailinger RL, Moore JB, Pawloski L, Cortes LRZ. Concepts of anemia among low income Nicaraguan women. Rev. Latino-am Enfermagem 2009; 17: 147-52.

[33] Galloway R, Dusch E, Elder L, Achadi E, Grajeda R, Hurtado E. Women's perceptions of ion deficiency and anemia prevention and control in eight developing countries. Soc. Sci Med2002; 55: $529-44$.

[34] Moore JB, Pawloski L, Rodriguez C, Lumbi L, Ailinger RL. The effect of nutrition education program on the nutritional knowledge, hemoglobin levels, and nutritional status of Nicaraguan adolescent girls. Pub Health Nurs 2009; 26: 144-52.

[35] Ailinger RL, Malloy S, Zamora L, Benavides C. Herbal remedies in a Nicaraguan barrio. J. Tanscultural Nurs 2004; 15: 278-82. 
[36] Barrett B. Herbal knowledge on Nicaragua's Atlantic coast: Consensus within diversity. J Commun Health 1995; 20: 403-21.

[37] Barrett B. Ethnomedical interactions: Health and identity on Nicaraguan's Atlantic coast. Soc Sci Med 1995; 40: 1611-21.

[38] Coe FG, Anderson GJ. Screening of medicinal plants used by the Garifuna of eastern Nicaragua for bioactive compounds. J Ethnoharmacol 1996; 53: 29-50

[39] Price J, Asgary R. Women's Health disparities in Honduras: Indicators and Determinants. J Women's Health 2011; 20: 1931-7.

[40] Arps S. Threats to safe motherhood in Honduran Miskito communities: Local perceptions of factors that contribute to maternal mortality. Soc Sci Med 2009; 69: 579-86.

[41] United Nations Population Fund (2007) Risking Death to Give Life in Panama's Tropical Forests: http://www.unfpa.org/public/site/ global/lang/en/pid/302. Accessed October1, 2012.

[42] Carter M, Speizer IS. Pregnancy Intentions Among Salvadoran Fathers: Results from the 2003 National Male Reproductive Health Survey. Int Family Plan Perspect 2005; 31: 179-82.

[43] Agurto I, Bishop A, Sánchez G, Betancourt Z, Robles S. Perceived barriers and benefits to cervical cancer screening in Latin America. Prevent Med 2004; 39(1): 91-8.

[44] Hernandez-Rauda R, Martinez-Garcia S. Osteoporosis-related life habits and knowledge about osteoporosis among women in El
Salvador: A cross-sectional study. BMC Musculoskel Disord 2004; 5: 29 .

[45] DiezPrimerasCausas mas Frecuentes de Morbilidad, Atendidas en ConsultaAmbulatoria (http://www.mspas.gob.sv/estadisticas2001. html), Accessed Spetember 15, 2009.

[46] Pan American Health Organization. Health in the Americas. Belize 2007. http://www.paho.org. Accessed October 14, 2012.

[47] Boyer DB, Klima C, Jennrich J. Midwifery in Northern Belize. J Midwifery Womens Health 2001; 46(1): 33-39.

[48] Parham L, de Rivera IL, Murillo W, et al. Short communication: high prevalence of drug resistance in HIV type 1-infected children born in Honduras and Belize 2001 to 2004. AIDS Res Hum Retroviruses 2011; 27(10): 1055-9.

[49] United Nations. UNAIDS Report on the Global AIDS Epidemic" 2010

[50] Malajovich L, Alcalde MA, Castagnaro K, Barroso C. Budget transparency on maternal health spending: a case study in five Latin American countries. Reprod Health Matters 2012; 20(39): 185-95.

[51] Berer M. Maternal Mortality and Morbidity: Is Pregnancy Getting Safer for Women? Reproduct. Health Matters 2007; 15: 6-16.

[52] Roth DM, Mbizvo MT. Promoting safe motherhood in the community: The case for strategies that include men. Afr. J. Reproduct Health 2001; 5: 10-21. 